Article (refereed) - postprint

Cutler, Nick A.; Chaput, Dominique L.; van der Gast, Christopher J. 2014.

\title{
Long-term changes in soil microbial communities during primary succession.
}

Copyright (C) 2013 Elsevier Ltd.

This version available http://nora.nerc.ac.uk/505071/

NERC has developed NORA to enable users to access research outputs wholly or partially funded by NERC. Copyright and other rights for material on this site are retained by the rights owners. Users should read the terms and conditions of use of this material at http://nora.nerc.ac.uk/policies.html\#access

NOTICE: this is the author's version of a work that was accepted for publication in Soil Biology and Biochemistry. Changes resulting from the publishing process, such as peer review, editing, corrections, structural formatting, and other quality control mechanisms may not be reflected in this document. Changes may have been made to this work since it was submitted for publication. A definitive version was subsequently published in Soil Biology and Biochemistry (2014), 69. 359-370. $\underline{10.1016 / \text { j.soilbio.2013.11.022 }}$

www.elsevier.com/

\section{Contact CEH NORA team at noraceh@ceh.ac.uk}

The NERC and CEH trademarks and logos ('the Trademarks') are registered trademarks of NERC in the UK and other countries, and may not be used without the prior written consent of the Trademark owner. 
1 Title:

2 Long-term changes in soil microbial communities during primary

3 succession

4

5 Nick A. Cutler ${ }^{a}{ }^{,}$, Dominique L. Chaput ${ }^{b}$, Christopher J. van der Gast ${ }^{c}$

6

$7 \quad{ }^{a}$ Scott Polar Research Institute, Lensfield Road, Cambridge, CB2 1EP, UK

$8{ }^{\mathrm{b}}$ Department of Mineral Sciences, Smithsonian Institution, National Museum of Natural

9 History, $10^{\text {th }}$ \& Constitution NW, Washington, DC 20560-119, USA

$10{ }^{\mathrm{c}}$ Centre for Ecology and Hydrology, Maclean Building, Benson Lane, Crowmarsh Gifford,

11 Wallingford, OX10 8BB, UK

12

$13{ }^{*}$ corresponding author

14 Address: Churchill College, Cambridge, CB3 ODS, UK

15 E-mail: nac37@cam.ac.uk

16 Telephone: +441223336202

$17 \quad$ Fax: +441223336180

18 


\section{Abstract}

Soil microbial communities (SMCs) play a critical role in the cycling of carbon and nutrients in terrestrial ecosystems, as well as regulating plant productivity and diversity. However, very little is known about long-term (decades-centuries) structural changes in these communities. The development of aboveground-belowground linkages during century-scale succession is also poorly understood. Our study addressed this knowledge gap by investigating SMC and plant communities undergoing primary succession on an 850-year chronosequence of lava flows in Iceland. We hypothesised that communities of microfungi and bacteria would respond to progressive changes in vegetation and that SMC diversity would increase with terrain age. Soil samples were collected from three lava flows at different stages of primary succession (165, 621 and 852 years after lava flow emplacement). Plant community composition was surveyed as the samples were collected. The composition of the SMCs present in the soil was determined using amplicon pyrosequencing. The physical and chemical properties of the soil were also analysed. The results of the study indicated changes in plant and fungal communities with increasing terrain age. Distinct plant and fungal assemblages were identified on the three sites and both communities became richer and more diverse with increasing terrain age. There was also evidence to suggest the development of mycorrhizal associations on older sites. In contrast, the composition and structure of the bacterial communities did not change systematically with terrain age. Similarly, there were few changes in soil properties: SOM concentrations and $\mathrm{pH}$, both of which have been demonstrated to be important to SMCs, were constant across the chronosequence. These results suggest that plant community composition is significant for fungal communities, but less relevant for bacterial communities. This finding has implications for studies of primary succession and the biogeochemical impact of vegetation change in high-latitude ecosystems.

Key words: Iceland; soil ecology; community assembly; plant-soil interactions; abovegroundbelowground linkages 
The changes that occur in plant and animal communities during primary succession (ecosystem development on terrain with no biological legacy) have been studied for decades (Walker and del Moral, 2003). However, very little is known about long-term (decadescenturies) primary succession in soil microbial communities (SMCs). SMCs play a critical role in the cycling of carbon and nutrients in terrestrial ecosystems as well as regulating plant productivity and diversity (van der Heijden et al., 2008). Understanding long-term changes in such communities is therefore essential to efforts to model and manage ecological change, including the restoration of degraded ecosystems (Kirk et al., 2004). Some attention has been given to changes in SMCs (particularly bacteria) over comparatively short periods of time (e.g. Jumpponen, 2003; Nemergut et al., 2007; Schütte et al., 2009; Sigler et al., 2002); the succession of mycorrhizal fungi over relatively short timescales has also received attention (Last et al., 1987). However, technological barriers (specifically, problems in describing the high diversity of microbial communities) have meant that, until recently, the focus his been on aggregate SMC function rather than taxonomy. Furthermore, the studies that have been published are largely based on glacial forelands (Schaaf et al., 2011). This study aims to address this gap by investigating SMC dynamics across an 850-year chronosequence of lava flows in Iceland. and Nicol et al. (2005) reported similar patterns for bacterial and archaeal communities, respectively. The functional diversity of SMCs may also increase as primary succession unfolds (e.g. Tscherko et al. 2003). However, these patterns are not universal. For example, Sigler et al. (2002) reported a decrease in bacterial diversity with increasing terrain age. 
could find no evidence of SMC succession; both studies stressed the importance of sitespecificity and stochastic effects in SMC assembly. The central research question posed by this study is therefore: do SMCs (specifically soil bacteria and fungi) undergo predictable changes, analogous to those observed in plant communities, during long-term (multi-century) primary succession? Based on existing studies, we hypothesised that:

$\mathrm{H} 1$ : changes in SMC composition would parallel changes in above-ground vegetation; hence, there would be progressive change in SMCs with terrain age, with distinct bacterial and fungal communities on sites at different stages of primary succession. $\mathrm{H} 2$ : the taxonomic diversity of fungal and bacterial communities would increase with terrain age, as ecosystem development progressed and new niches (e.g. different types of organic substrate) became available.

\section{$2 \quad$ Materials and Methods}

Soil samples were collected from three lava flows at different stages of primary succession. Plant community composition was surveyed as the samples were collected. The composition of the SMCs present in the soil was determined by amplicon pyrosequencing. The physical and chemical properties of the soil, both of which are important to SMCs, were also analysed.

\subsection{Study sites}

It is clearly difficult to observe long-term ecosystem development directly, necessitating the use of space-for-time substitution (chronosequences) to infer multi-century ecological change (Walker et al., 2010). The use of chronosequences is well-established in ecology and soil science (Matthews, 1992; Stevens and Walker, 1970; Walker et al., 2010; Wardle et al., 2004). This study utilised to a well-dated chronosequence of lava flows on Mt Hekla, Iceland 
$\left(64^{\circ} 00^{\prime} \mathrm{N}, 19^{\circ} 40^{\prime} \mathrm{W}\right)$ to investigate long-term (multi-century) changes in SMC composition.

106

107

108

109

110

The chronosequence has been described in detail in Bjarnason (1991) and Cutler et al. (2008). The Hekla sites are particularly well-suited to chronosequence studies as a) the age of the lava flows is well constrained (to a sub-annual level in some cases); b) the lava flows are close to each other and at the same altitude, ensuring that the sites have similar environmental conditions and accessibility to propagules and c) the lava flows have similar slopes, substrate chemistry and surface physiogonomy (Bjarnason, 1991). The region has a cool, maritime climate with mean January and July air temperatures of $-1.7^{\circ} \mathrm{C}$ and $11.0^{\circ} \mathrm{C}$, respectively, and a mean annual rainfall of around $1200 \mathrm{~mm}$. The lava flows varied in age (165-852 years) but were otherwise similar in all respects. Younger lava flows do exist (e.g. those emplaced in the 1980 and 1947 CE eruptions of Mt Hekla), but these flows do not have soil cover and were therefore omitted from this study. The lava has been dated by contemporary accounts and tephrochronology (Thorarinsson 1967), giving excellent age constraint. All of the flows have an altitude around $300 \mathrm{~m}$ above sea level and are composed of blocky, a'a lava with a similar geochemistry. The survey sites used are characterised by fine, free-draining andosols (Arnalds, 2004). The lava flows undergo slow vegetation succession (Bjarnason, 1991). The vegetation on the younger surfaces is dominated by a thick mat of the moss Racomitrium lanuginosum with scattered patches of the pioneer lichen Stereocaulon vesuvianum. Vascular plants establish on surfaces $\sim 100$ years old and increase in abundance with terrain age. The oldest surfaces are characterised by hardy shrubs, notably willow (e.g. Salix phylicifolia), birch (Betula pubescens) and ericaceous shrubs such as Vaccinium spp. Plant taxonomic richness and diversity increase monotonically across the chronosequence (Cutler, 2010).

\subsection{Sampling}

Soil samples were collected from lava flows emplaced in 1845, 1389 and 1158 CE (i.e. surfaces that were 165, 621 and 852 years old in August 2010) (Fig. 1). Two transect lines were established on flat sites on each flow. Each transect line comprised three $2 \mathrm{~m} \times 2 \mathrm{~m}$ quadrats $10 \mathrm{~m}$ apart. Soil samples were collected from two opposing corners of the quadrats, 
resulting in a total of six samples per transect and 36 samples in total. Sampling was carried

out on a scale relevant to the spatial scale of the vegetation ( $\mathrm{cm}$ to $\mathrm{m}$ ) and the sampling strategy aimed for a balance between spatial resolution and coverage, within the available resources. A soil core approximately $2 \mathrm{~cm}$ in diameter and $10 \mathrm{~cm}$ long was collected at each sampling location using a stainless steel corer. The corer was sterilised using a $70 \%$ solution of ethanol before and after the collection of each core. The core was immediately placed in a sterile sample bag and stored at $-20^{\circ} \mathrm{C}$ within hours of collection. On the 1389 and 1158 flows, there was a clear distinction between an organic layer, primarily formed of partially decomposed moss stems, and an underlying layer with a sandy texture. These two layers were separated in the field and stored in separate sterile bags. Vegetation composition and abundance was recorded for each quadrat, using the Braun-Blanquet scale, with taxonomy following Kristinsson (1998). No fungal fruiting bodies were observed in the quadrats during the sampling.

Fig. 1: Site plan

\subsection{Soil analysis}

Grain size distribution was analysed using a laser particle sizer in accordance with the manufacturer's instructions (Malvern Mastersizer 2000, Malvern Instruments Ltd, Malvern, UK). Soil organic matter (SOM) content was determined by loss on ignition (LOI) measurements. Samples were dried at $105^{\circ} \mathrm{C}$ overnight to drive off moisture, then heated to $550^{\circ} \mathrm{C}$ for four hours to determine the organic content (Heiri et al., 2001). Total concentrations of soil phosphorus, potassium, magnesium and calcium (hereafter, the format [nutrient] is used to indicate nutrient concentrations) were determined by inductively coupled plasma optical emission spectrometry (ICP-OES), using an Optima 2100 DV (Perkin Elmer, Waltham, MA), following digestion in aqua regia $\left(6 \mathrm{ml} 70 \% \mathrm{HCl}\right.$ and $\left.2 \mathrm{ml} 70 \% \mathrm{HNO}_{3}\right)$ heated to $105^{\circ} \mathrm{C}$ (Chen and $\left.\mathrm{Ma}, 2001\right)$. In addition to the soil samples, material from the organic layers present on the 1389 and 1158 sites was also analysed for comparison (five samples from each site). Soil pH was determined using an Orion 410A electronic $\mathrm{pH}$ meter (Thermo 
163

164

165

166

167

168

169

170

171

172

173

174

175

176

177

178

179

180

181

182

183

184

185

186

187

188

189

Fisher Scientific, Waltham, MA): $1 \mathrm{~g}$ of soil was mixed with $5 \mathrm{ml}$ of deionised water, shaken, sonicated with ultrasound for $15 \mathrm{mins}$ then left to stand for $30 \mathrm{~min}$. before the measurements were taken.

\subsection{Molecular analysis}

A modified CTAB extraction method (Rogers and Bendich, 1988) was used to extract microbial DNA from the soil samples. Each core was thawed at room temperature and thoroughly mixed; $500 \mu$ l lysis buffer $(0.5 \%$ SDS, $25 \mathrm{mM}$ EDTA, $20 \mu \mathrm{g} / \mathrm{ml}$ proteinase $\mathrm{K})$ was then added to $\sim 0.4 \mathrm{~g}$ subsample of the soil, mixed by inversion and incubated at $55^{\circ} \mathrm{C}$ for 30 minutes, mixing every 10 minutes. $100 \mu \mathrm{l}$ of $5 \mathrm{M} \mathrm{NaCl}$ and $80 \mu \mathrm{l}$ of $10 \% \mathrm{CTAB}$ solution at $65^{\circ} \mathrm{C}$ were added and the samples incubated at $65^{\circ} \mathrm{C}$ for 10 minutes. $680 \mu \mathrm{l}$ of chloroform:isoamyl alcohol (24:1) was then added; the mixture was shaken to form an emulsion, then centrifuged for 5 minutes at $16000 \times \mathrm{g}$ at $20^{\circ} \mathrm{C}$. Nucleic acids were precipitated from the aqueous layer by adding 0.6 volumes of isopropanol. The mixture was left for 2 hours at room temperature, then pelleted by centrifugation for 30 minutes at 14680 $x g$ at $20^{\circ} \mathrm{C}$, washed with $100 \mu \mathrm{l}$ of $70 \%$ ethanol and left to air dry for one hour. Pellets were resuspended in $50 \mu \mathrm{l} \mathrm{H}_{2} \mathrm{O}$ and stored at $-20^{\circ} \mathrm{C}$. The DNA yield of each sample was estimated by analysing $1 \mu \mathrm{l}$ of extract on a NanoDrop $8000^{\mathrm{TM}}$ multi-sample spectrophotometer (Thermo Scientific, Waltham, MA). Aliquots of $45 \mu$ l were drawn from each sample and cleaned with Powerclean kits (MoBio Laboratories Inc, Carlsbad, CA) in accordance with the manufacturer's instructions. The cleaned DNA solutions were then combined according to transect to produce six pooled samples designated HK-1 to HK-6 (i.e. each pooled sample comprised six sub-samples, two from each of the three quadrats in the transect). HK-1 \& -2 represented the two transects from the 1845 flow (165 years old), HK-3 \& -4 the 1389 flow (621 years) and HK-5 \& -6 the 1158 flow (852 years: refer to Table 1 for further clarification). The pooled samples were concentrated using centrifugal filter devices (Millipore, Billerica, $\mathrm{MA}$ ) and standardised to a DNA concentration of $20 \mathrm{ng} / \mu \mathrm{l}$ prior to sequencing. 
191

192

193

194

195

196

197

198

199

200

201

202

203

204

205

206

207

208

209

210

211

212

213

214

215

216

217

218

219

Tag-encoded FLX amplicon pyrosequencing was used to investigate the composition of the fungal and bacterial communities in the soil. For fungi, a $\sim 700$ bp region spanning the internal transcribed spacer 1 (ITS1), 5.8S ribosomal RNA (rRNA) and ITS2 was amplified using the primers ITS1F and ITS4 (Gardes and Bruns, 1993; Lord et al., 2002; White et al., 1990). For bacteria, a 500 bp region of the $16 \mathrm{~S}$ small subunit ribosomal RNA (SSU rRNA) was amplified using primers E104-120 (Wang and Qian, 2009) and 530R (Muyzer et al., 1993). Pyrosequencing was carried out at the Research and Testing Laboratory (RTL, Lubbock, TX) on the Roche 454 FLX Titanium platform (454 Life Sciences, Branford, CT). All analyses were performed at the Research and Testing Laboratory (454 Life Sciences, Bradford, CT), based upon RTL protocols.

Bacterial 16S rRNA sequence analysis was carried out in mothur 1.31.1 (Schloss et al., 2009) following the recommendations of Schloss et al. (Schloss et al., 2011). Flow, quality and fasta files were extracted from the sff file. All flow files were trimmed to maximum and minimum lengths of 360 and 720 flows, settings recommended by Quince et al. (2011). They were denoised with shhh.flows, the mothur implementation of PyroNoise (Quince et al., 2009). Primer and barcodes were removed and sequences shorter than 200 bp or with homopolymers greater than 8 bp were discarded. The remaining sequences were aligned using the SILVA bacterial reference alignment (Quast et al., 2013). Only sequences spanning the targeted region of 16S rRNA were kept and all sequences were trimmed to the same length (determined by optimising alignment end and minimum sequence length so as to keep $90 \%$ of sequences). Data were further denoised by clustering together sequences with 1 bp difference per 100 bp and chimeras were removed using the mothur implementation of uchime (Edgar et al., 2011), with the more abundant sequences as reference. Sequences were classified against the SILVA bacterial reference database using the Wang method (Wang et al., 2007) with kmer size 8, 100 bootstrap iterations and a cutoff value of $60 \%$ for taxonomic alignment. Those identified as organelles, Archaea or Eukarya were removed. Mothur was used to cluster sequences into operational taxonomic units (OTUs) at a 97\% similarity level, approximately corresponding to species level. 
221 Processing and analysis of the ITS sequences followed a pipeline similar to that of $16 \mathrm{~S}$ rRNA, with the following differences. After denoising with shhh.flows and removing the primers and barcodes, fungal sequences shorter than 150 bp were removed (the lower minimum length for fungi was chosen due to the wide variability that is common in the fungal ITS1 region). Following this initial clean-up, the ITS1 region was extracted using the ITS

Extractor tool on the PlutoF Workbench (Abarenkov et al., 2010b; Nilsson et al., 2010) and sequences shorter than $100 \mathrm{bp}$ following this step were discarded. Chimeras were removed using the mothur implementation of uchime and sequences were subsampled to the size of the smallest group. Sequences were clustered into OTUs at a $93 \%$ similarity level, based on the average sequence divergence between named species in GenBank (Hibbett et al., 2011). For OTU clustering, a distance matrix was constructed in mothur using pairwise distance values, with consecutive gaps treated as one and ignoring gaps at the end of pairs. The UNITE+INSDC fungal ITS database (Abarenkov et al., 2010a) was used as a reference for classification, with the following modifications. All entries without kingdom-level information in the UNITE lineage column were removed, as were all entries with ambiguous bases. The modified database, split into separate fasta and taxonomy files and formatted for the use of mothur, contained 16279 entries. Classification against this database was carried out in mothur as described above but with a cutoff value of $50 \%$ for taxonomic alignment, due to the greater variability of ITS1. The following discussion of fungal varieties concentrates on taxa that a) accounted for at least $1 \%$ of reads (summed across all sites) and b) were resolved to a genus level or lower.

243 In previous environmental studies using amplicon pyrosequencing data, researchers have 244 assumed a correlation between the proportion of sequence reads for a given OTU and the 245 relative abundance of that OTU in the community sampled, allowing diversity indices to be 246 calculated (see Blaalid et al., 2012; Uroz et al., 2012 for examples of this approach).

247 Technological artefacts in the pyrosequencing process, as well as innate biological traits of 248 the organisms under consideration, may bias the relative quantification of taxa (Amend et al., 
2010); however, it is still possible to use pyrosequencing data in a semi-quantitative way. At

250

251

252

253

254

255

256

257

258

259

260

261

262

263

264

265

266

267

268

269

270

271

272

273

274

275

276

277

the very least, it should be possible to compare the proportional abundance of a given taxon across samples, because the variables that bias quantification are consistent within taxa (Amend et al., 2010). Consequently, we have included relative abundance figures based on the pyrosequencing data as a first-order estimation of community diversity.

\subsubsection{Accession numbers}

Sequence data were uploaded with MIMARKS-compliant metadata to the NCBI Sequence Read Archive under Bioproject number PRJNA210080.

\subsection{Statistical analyses}

The Braun-Blanquet values recorded for the vegetation were transformed to percentage cover by taking the midpoints of the classes. The transformed values were then used to calculate Shannon diversity indices $(H)$ for the vegetation in each quadrat. Random selection (without replacement) was used to standardise the number of sequence reads in each sample, prior to the calculation of microbial diversity. Using this technique, all samples (both fungal and bacterial) were reduced to the number of reads present in the smallest sample. Non-metric multidimensional scaling (NMDS), a robust ordination technique, was used to graphically represent vegetation and molecular data, based on OTU abundance data in each case. Detrended correspondence analysis was applied to the same data sets. The multivariate analyses of the molecular data were based on OTUs with $\geq 1 \%$ of the sequence reads in any given sample. Both the NMDS and DCA analyses were carried out using the vegan package running in $\mathrm{R}$ (Oksanen et al., 2010). Percent similarity $(P S)$, a robust index of compositional similarity, was used to compare the plant species and OTU assemblages in different quadrats (Faith et al., 1987). The analysis was based on abundance data (plants) and presence-absence matrices (microbes). PS was calculated using the Bray-Curtis dissimilarity metric for abundance data; the Sorenson dissimilarity metric (Sørensen, 1948) was used with presence-absence data. 


\section{$3 \quad$ Results}

\subsection{Vegetation \& soils}

283 A total of 33 higher plant and cryptogam species were recorded, including 24 vascular plants 284 (7 shrubs, 9 gramminoids and 8 forbs); 3 bryophytes and 6 lichens (Table 1). The bryophyte 285 Racomitrium lanuginosum was overwhelmingly dominant with $>75 \%$ cover in most quadrats, 286 although there were changes in vegetation structure according to terrain age. Whilst the moss layer was more-or-less uninterrupted on the youngest sites, higher plants were more prominent on older sites. Plant richness and Shannon diversity were relatively low on all sites, but both metrics increased monotonically with terrain age as higher plants became established (Fig. 2). NMDS of the vegetation data (performed using presence-absence figures) highlighted compositional differences: the sites were clustered according to terrain age, but distributed along axis NMDS-1 and clearly distinct from one another (Fig. 3). The first axis generated by DCA was closely associated with terrain age and explained $23 \%$ of the variance in the data (results not shown). The length of this axis was $\sim 3$ SD units. The $P S$ figures indicated high levels of similarity between transects on the same lava flow and a clear difference between flows of different ages (Table 4).

Table 1: Vegetation cover data

299 Fig. 2: Plant diversity plots

300 Fig. 3: Plants NMDS

302 There were no significant differences in the physical properties of the soils according to 303 terrain age. All the soil samples were dark, fine-grained and had low cohesion. The fine sand 304 fraction $(2-200 \mu \mathrm{m})$ accounted for $70-75 \%$ of grains by volume in all samples (Table 2$)$. The 305 grain size distribution of the 1389 and 1158 samples was virtually identical, consisting of 
$\sim 95 \%$ sand-sized particles and 5\% silt. Clay sized particles were absent. The 1845 samples were somewhat finer and contained small amounts of clay $(\sim 0.3 \%$ by volume). All of the samples were weakly acidic ( $\mathrm{pH} \sim 6.5)$ and comprised around 10\% SOM.

Total soil $\mathrm{N}$, determined using an elemental analyzer, was low and averaged around $0.1 \%$ on all three lava flows (Table 2). Total soil $\mathrm{P}$, measured using ICP, exhibited a significant increase with terrain age (ANOVA: $F_{2,33}=17.9, p<0.001$ ). Mean $[\mathrm{K}]$, [Mg] and $[\mathrm{Ca}]$ were lower and did not change systematically with terrain age. There were significant correlations between $[\mathrm{K}],[\mathrm{Mg}]$ and $[\mathrm{Ca}]$ (Spearman-rank: $[\mathrm{K}],[\mathrm{Ca}] \rho=0.97, \mathrm{p}<0.001 ;[\mathrm{K}],[\mathrm{Ca}] \rho=0.95$, $p<0.001$ ). Concentrations of $P$ and $K$ in the organic horizon present on the 1389 and 1158 flows were much lower than those in the underlying mineral soils (Table 2).

Table 2: Soil characteristics

\subsection{Microbial communities}

The number of sequence reads did not vary widely between samples; the bacterial samples generated more sequences than the fungal samples (ranges: 2046 - 4152 reads/transect for fungi, 4069 - 5099 for bacteria). Following sequence clean-up, the median length was 270 base pairs (bp) for the fungi and $281 \mathrm{bp}$ for the bacteria. The proportion of sequences that remained unclassified at a phylum level was relatively small $(2.4 \%$ of the fungal reads and $5.4 \%$ of the bacterial reads).

The fungal communities comprised a mixture of taxa from the Basidiomycota and Ascomycota, with more reads from the Ascomycota (a ratio of 2.6:1). Other phyla were present but rare: only the Zygomycota (in the form of the genus Mortierella sp.) had a significant representation (refer to Supplementary data for details). A small number of fungal taxa accounted for $>1 \%$ of reads and could be resolved to genus level or lower (Table 3 ). Although few in number, these taxa accounted for a disproportionate number of reads $(36.2 \%)$. The bulk of the remaining reads were assigned to less well resolved taxa, notably 
three unclassified Ascomycetes (one from the subphylum Pezizomycota, one from the order Capnodiales and one from the order Helotiales, accounting for $26.8 \%, 8.1 \%$ and $5.0 \%$ of all fungal reads, respectively) and an unclassified Basidiomycete from the subphylum Agaricomycetes (5.0\% of all fungal reads). The remaining reads were dispersed thinly across a large number of taxa (refer to the Supplementary Data file for details). Large numbers of reads associated with Batcheloromyces sp. (a genus from the order Capnodiales) were recorded on the older surfaces (the 1389 and 1158 flows), but fewer were recorded on the youngest terrain (Table 3). Indeed, virtually no reads from the Capnodiales were obtained from the youngest lava flows, despite the general abundance of reads from this order. Hygrocybe spp. were common on the youngest terrain but less abundant on older surfaces; a similar pattern was observed with Clavaria argillacea. Conversely, sequence reads associated with the genera Cryptococcus and Epicoccum were absent on the youngest sites,

347 but abundant on the two older flows.

Matches were obtained with 16 fungal genera linked with mycorrhizal activity. Most of the matches were from the Basidiomycota. With the notable exception of Meliniomyces bicolor. 351 (an ericoid mycorrhizal (ERM) fungus), the overwhelming majority of these genera (14) were 352 connected with ectomycorrhizal (ECM) associations (Rinaldi et al., 2008). Two taxa of 353 arbuscular mycorrhizal (AM) fungi were identified, but they were exceptionally rare (a total of 354 five reads across all the sites) and presumably of limited ecological importance. On the 355 whole, sequences from putative mycorrhizal genera were not abundant: only reads associated with the genera Meliniomyces and Russula appeared in any great number.

357 However, when the data were aggregated there was a clear relationship between the 358 frequency of putative mycorrhizal reads and terrain age (Fig. 4). Mycorrhizal fungi were 359 almost entirely absent from the youngest lava flow (HK-1 \& HK-2) and much more common 360 on the oldest terrain (HK-5 \& -6). Six of the putative mycorrhizal genera only occurred on the 361 oldest terrain. All of the reads associated with Russula aeruginea (an ECM fungus that forms associations with birch trees) and $96 \%$ of those associated with Melinionmyces bicolour 
(which has been demonstrated to form symbiotic associations with ericoid shrubs, specifically Vaccinium sp. (Grelet et al., 2009)) were from the oldest lava flow.

Fig. 4: Abundance of putative mycorrhizal taxa

The analysis revealed 24 bacterial phyla. Phyla commonly associated with soil habitats, notably Proteobacteria and Acidobacteria, were dominant in terms of number of reads (Table 3). Betaproteobacteria from the class Burkholderiales were particularly prominent, as were Alphaproteobacteria from the order Rhizobiales. Actinobacteria (including Arthrobacter sp., a common soil bacterium) were also abundant. The other bacterial phyla had many fewer sequence reads. For example, the Verrucomicrobia, commonly encountered in other surveys of soil bacteria (Killham, 1994), accounted for less than $2 \%$ of all the bacterial sequence reads. The relative abundance of sequence reads from the Acidobacteria was lowest on the oldest terrain age, even though soil $\mathrm{pH}$ remained constant. The abundance of Actinobacteria increased somewhat with terrain age. Otherwise, there were no obvious trends in the representation of other abundant bacterial phyla.

Table 3: Pyrosequencing summary

The bacterial communities sampled were richer than their fungal counterparts (Fig. 5). The pyrosequencing data suggested that both communities were inequitable i.e. they were characterised by a small number of dominant taxa. For fungi, top quintile of OTUs (ranked by number of sequences) accounted for $85 \%$ of total reads. Dominance was less marked in the bacteria, where the top quintile of OTUs accounted for $76 \%$ of total sequence reads.

387 Consequently, bacterial communities were more diverse than fungal communities. Fungal 388 richness and Shannon diversity increased with terrain age (diversity on the 1158 flow $(H=$ $3894.53)$ was slightly higher than that on the 1389 flow $(H=4.47 \pm 0.02))$. Fungal equitability was higher on the two oldest surfaces (HK-3 to HK-6). Similar indices of bacterial diversity were much less variable and did not increase in the same fashion with terrain age. 
393 Fig. 5: Microbial richness, diversity \& equitability data

394

395 The NMDS plot of the fungal data indicated close similarities between communities on the 396 oldest terrain (HK-3 to HK-6) (Fig. 6) In contrast, the transects from the youngest surface 397 (HK-1 \& HK-2) were widely separated, both from each other and the older transects. End398 member transects were separated by $~ 3.5$ SD units on the first DCA axis, which accounted 399 for $36 \%$ of the variance in the data.

400

401

The NMDS plot for the bacterial data indicated similarities between transects on the same 402 lava flow. The transects were arranged along NMDS1 according to terrain age (Fig. 6).

403 Again, transects from the youngest surface (HK-1 and HK-2) appeared dissimilar. However, 404 the overall differences between transects were less for bacteria than fungi. DCA indicated 405 that end member sites were only separated by $\sim 1.5$ SD units on the first DCA axis, which 406 accounted for $45 \%$ of the variance in the data.

407

408

Fig. 6: Fungal and bacterial NMDS plots

409

410 The $P S$ values for fungal communities reinforced the pattern evident on the NMDS plot i.e.

411 the communities from transects HK-3 to HK-6 were very similar and distinct from those on 412 the youngest terrain (Table 4). On the youngest lava flow, the similarity between HK-1 and 413 HK-2 was low (63\%) when compared to the transects on older surfaces. HK-1 and HK-6 414 were remarkably similar in terms of fungal communities, but not plants and bacteria. The 415 pattern of similarity was different for the bacteria. A large proportion of bacterial OTUs 416 occurred across the chronosequence. Consequently, the similarities between bacterial 417 communities in different sampling locations were remarkably high and there was little 418 evidence of systematic differences according to terrain age. Transects on terrain of the same 419 age were more-or-less the same as sites on terrain of different ages in terms of community 420 composition. 


\section{Discussion}

The results of this study indicated changes in plant and fungal communities with increasing terrain age. Distinct plant assemblages were identified on the three lava flows and the fungal communities on the youngest lava flow were very different from those on the older flows.

Both plant and fungal communities became richer and more diverse with increasing terrain age. There was also evidence to suggest the development of mycorrhizal associations on older sites. In contrast, the composition and structure of the bacterial communities did not change markedly with terrain age and there were few changes in soil properties. SOM concentrations and $\mathrm{pH}$, both of which have been demonstrated to be important to SMCs (e.g. Griffiths et al., 2011), were constant across the chronosequence. These results suggest that changes in plant community composition during the later stages of primary succession are significant for fungal communities, but less relevant for bacterial communities.

The results of this study indicated slow, progressive change in plant communities, consistent with previous studies from this location (Bjarnason, 1991; Cutler et al., 2008). Although plant species from the regional pool are gradually added during succession, the main changes to the vegetation are structural rather than functional i.e. a transition in dominance from the 442 moss layer to shrubby vegetation (Cutler, 2010). The Racomitrium moss layer is a significant component of the vegetation across the chronosequence. It is probably a major contributor of organic carbon to the soil, although decomposition rates are likely to be slow, due to low prevailing temperatures and poor litter quality (Cutler, 2011). Shrubby taxa appear on Hekla's lava flows after $\sim 100$ years of primary succession, but they do not become abundant until 447 dense birch and willow thickets form on terrain $>500$ years old. 
Changes in soil properties frequently accompany primary plant succession. Typically, $\mathrm{N}$ and organic matter accumulate, cation concentrations decrease and soils become more acidic (Chapin et al., 1994; Matthews, 1992; Walker and del Moral, 2003). However, in this case there was little evidence for progressive changes in soil properties: SOM concentrations, $\mathrm{pH}$ and major cation concentrations remained constant. Total soil phosphorus did increase, a pattern that has also been observed in foliar nutrient concentrations in mosses from this location (Cutler, 2011).

Low levels of biotic reaction may explain the absence of progressive change in soil properties. Most $\mathrm{N}$ fixation is probably carried out by free-living microbes (primarily cyanobacteria) living in the moss layer (Henriksson et al., 1987), or in symbiosis with lichens e.g. Stereocaulon vesuvianum and Peltigera spp. (Vitousek, 1994). Much of this N capital is likely to remain conserved in moss tissue (DeLuca et al., 2002). Nitrogen fixing bacteria (e.g. taxa from the family Bradyrhizobiaceae) were identified. However, these organisms only fix $\mathrm{N}$ in association with a symbiont. There are no leguminous or actino-rhizal plants on the study sites so soil $[\mathrm{N}]$ is likely to remain low as a result (Cutler, 2011).

The deposition of allocthonous material (dust and volcanic ash) by the wind is also likely to play an important role in soil development (or the lack thereof) on the lava flows. Southern Iceland suffers from soil erosion, resulting in high atmospheric dust loads (Arnalds et al., 2012; Greipsson, 2012) and the moss layer on the sites is likely to trap some of this material. Hence, the mineral component of Hekla's soils is mainly derived from aeolian deposition,

471 rather than bedrock weathering (Arnalds, 2004). Differences between nutrient cation and P

472 concentrations in the organic layer (with a low minerogenic component) and underlying 473 mineral soil (where dust accumulates) suggested that the addition of aeolian material 474 influences soil fertility (Table 2). Although decomposition rates are likely to be low, 475 accumulating SOM is continuously diluted by the addition of minerogenic material, hence 476 SOM concentrations do not vary with terrain age, even though standing biomass does. 477 Mobile cations are presumably also replenished by same route. Counter to expectations, [K], 
$[\mathrm{Mg}]$ and $[\mathrm{Ca}]$ did not vary with terrain age, despite rainfall levels that would promote

479

480

481

482

483

484

485

486

487

488

489

490

491

492

493

494

495

496

497

498

499

500

501

502

503

504

505

506

leaching, suggesting continuous replenishment and cation levels in excess of plant requirements. Previous work on the N:P ratios of plant tissue suggest that it is $\mathrm{N}$, rather than $P$, that is limiting, and $P$ is also likely to be present in excess of plant requirements (Cutler, 2011). The continual addition of $P$ not required by plants and the transformation of this mineral to recalcitrant forms, would lead to the observed increases in total $P$. The accumulation of aeolian dust may also buffer soil $\mathrm{pH}$, preventing progressive acidification.

\subsection{Changes in SMC composition [H1]}

It was expected that changes in SMC composition would mirror changes in above-ground vegetation. Plants can influence both the physical and chemical properties of the soil environment in a number of different ways, notably through root growth and the production of litter and root exudates (van der Heijden et al., 2008). Previous research has demonstrated close links between plant community composition and SMC structure, although it is not always clear whether plants structure microbial communities or vice versa (Read, 1994). For example, Knelman et al. (2012) found that plants played a central role in structuring bacterial communities in the earliest stages of primary succession and that SMCs varied according to plant type. Ohtonen et al. (1999) reported similar findings over a longer timescale and Mitchell et al. (2010) demonstrated the impact of vegetation change (in this case, the establishment of birch trees in upland heath vegetation) on SMC structure and function. It might therefore be expected that as plant communities undergo succession, SMCs respond to the changing environmental conditions that result (Bardgett et al., 2005).

The microbial communities in this study exhibited differing developmental trajectories. In common with plant communities, fungal assemblages appeared to change as terrain age increased. In contrast, bacterial communities remained very similar in terms of composition across the chronosequence. The fungal NMDS plot (Fig. 6a) suggested a change in community composition between the youngest transects (HK-1 \& HK-2) and the older surfaces. A difference of 4 SD units in a DCA plot indicates more-or-less complete turnover, 
so there are clearly differences between early and late successional communities. This

508 observation is suggestive of microfungal succession, which slows as the terrain age

509 increases. The increase in community similarity that occurs with terrain age (Table 4) is

510 consistent with convergent succession i.e. young sites have spatially heterogeneous

511 distributions of taxa that are homogenised as succession progresses (Lepš and Rejmánek,

512 1991; Woods, 2007). The similarity between fungal communities on the youngest and oldest

513 sites (HK-1 and HK-6: Table 4) apparently goes against this trend, but the relationship

514 between the sites is driven by the co-occurrence of many rare OTUs (over-weighted due the

515 use of presence-absence data). The widely separated position of the sites on the NMDS plot,

516 which is based on more abundant (and, presumably, more ecologically important, OTUs)

517 suggests that the similarity between these sites is an artefact of the technique used.

518 Microfungal succession has been observed before: Osana and Trofymow (2012), for

519 example, reported succession in saprotrophic fungi living in moss, but this process has not,

520 to our knowledge, been observed on a timescale of centuries.

521

522 It is likely that mycorrhizal associations are particularly important in primary successions,

523 given the stressful growth conditions (particularly low $\mathrm{N}$ availability) that typically prevail

524 (Walker and del Moral, 2003). ERM and ECM fungi would be expected to dominate, due to

525 the scarcity of $\mathrm{N}$ and the fact that most bioavailable $\mathrm{N}$ is likely to be tied up in organic

526 macromolecules. Previous research has suggested that AM fungi do best in mineral soils

527 where the availability of $P$ is low relative to $N$ (Read, 1994), so they are likely to be less

528 abundant on Hekla (where $\mathrm{P}$ is probably not limiting). A temporal shift in the abundance of

529 mycorrhizal taxa might also be anticipated as vascular plants colonise, spread and form

530 mycorrhizal associations over time (Bardgett et al., 2005). Jumpponen (2003) hypothesised

531 that early successional communities would be dominated by saprotrophic Ascomycetes and

532 Basidiomycetes, whereas fungal communities on older substrates would be characterised by

533 mycorrhizal fungi associated with plant roots. Read (1994) noted that whilst early plant

534 colonisers are typically non-mycorrhizal, the herbaceous species that dominate the 
intermediate stages have a facultative requirement for $\mathrm{AM}$ and the trees and shrubs characteristic of late succession frequently have an obligate need for ECM.

538 Mycorrhizal taxa were not especially abundant in this study (perhaps because plant roots 539 were not sampled directly) but there was some evidence to support the trends identified in 540 earlier studies. AM fungi were scarce and ECM and ERM fungi were found on the oldest 541 sites e.g. the occurrence of $R$. aeruginea and $M$. bicolour in association with shrub and tree 542 species on the 1158 lava flow (samples HK-5 \& -6). Furthermore, it appeared that 543 mycorrhizal taxa were more abundant on the oldest terrain (Fig. 5). It was impossible to establish definitively how many of the fungi observed were saprotrophs, due to the variations

545 in taxonomic resolution and uncertainties over fungal metabolism in the published literature.

546 Two of the most abundant fungal taxa may be confidently described as saprotrophs

547 (Mortierella sp. and Clavaria argillacea) and other, rarer saprotrophs were present on terrain 548 of all ages. Clavaria argillacea appeared to decline in abundance with increasing terrain age 549 (Table 3), consistent with predictions of Jumpponen (2003), but Mortierella exhibited the 550 opposite pattern. Ultimately, it was not possible to establish saprotrophic succession with 551 such limited data and a more focussed study would be required to establish whether the 552 relative proportion of saprotrophs changes systematically with successional stage.

554 The bacterial communities exhibited very little evidence of succession. The lava flows were 555 arranged in age order along the first NMDS axis (Fig. 6), which is consistent with succession. 556 However, the most abundant bacterial OTUs occurred on all three sites and short DCA axes 557 ( 1.5 SD units) indicated low species turnover. The composition of the bacterial community 558 was not unexpected and most of the major groups commonly associated with soils were 559 present. Only the Acidobacteria and Actinobacteria exhibited a systematic change in 560 abundance with terrain age. It may be that the bacterial communities reach a long-term 561 equilibrium relatively early in the succession. Studies elsewhere have indicated that bacterial 562 communities can stabilise after a period of decades (e.g. Tscherko et al., 2003). In this study, bacterial communities may have stabilised with the formation of continuous moss cover and 
564 the associated accumulation of the first protosoils $\sim 70$ years after the emplacement of the 565 lava. At that point, cyanobacterial communities living on the surface of the lava would have

566

567

568

569

570

571

572

573

574

575

576

577

578

579

580

581

582

583

584

585

586

587

588

589

590

591

been replaced by heterotrophic bacteria as light was excluded and the moss provided a reliable, if meagre, source of organic carbon. Thereafter, the progressive changes in soil conditions that influence bacterial community composition and structure on other sites (e.g. increasing soil $\mathrm{pH}$ ) did not occur and the bacterial community remained relatively unchanged.

\subsection{Changes in SMC structure [H2]}

The SMCs were characterised by high levels of richness and a large number of rare OTUs (the 'rare biosphere'). Pyrosequencing is a sensitive technique and these patterns are common in molecular analyses of environmental samples. Because of the spatially heterogeneous nature of soils, the use of small $(<1 \mathrm{~g})$ samples may have biased the results of microbial analyses, favouring the detection of dominant species (Kirk et al., 2004). The results of this study are therefore likely to underestimate true microbial diversity. For example, transect HK-2 had anomalously low fungal diversity, but this was due to an exceptionally large number of reads for two OTUs (both from the sub-phylum Pezizomycotina but unclassified below this level).

Hypothesis $\mathrm{H} 2$ proposed that the taxonomic diversity of fungal and bacterial communities would increase with terrain age, as ecosystem development progressed and new niche space became available. Plant richness, diversity and equitability all increased with terrain age. These changes represent a 'filling up' of the sites from a small regional species pool and decreasing dominance of $R$. lanuginosum as vascular plants colonise and expand (Cutler et al., 2008). Differences in dispersal and establishment ability probably played a role in determining the rate and direction of plant succession. The relationship between SMC structure and terrain age varied according to the group studied. Fungal community structure paralleled changes in above ground vegetation, with monotonic increases in diversity with increasing terrain age. This result supported previous research that suggests SMC diversity 
592 is linked to plant species diversity (Zak et al., 2003). In contrast, bacterial community

593 structure did not change in step with vegetation succession.

594

595 In microbial ecology, it has been posited that "everything is everywhere but the environment

596 selects" (Green and Bohannan, 2006). As fungi readily disperse by spores, increasing fungal

597 richness is most likely due to the creation of new habitat niches as succession unfolds. New

598 niches created by plant succession might include the presence of recalcitrant organic

599 compounds, e.g. lignin, in litter, or the roots of new colonisers e.g. ericaceous shrubs. Some

600 mycorrhizal fungi, particularly the ECM and ERM fungi that predominant in the latter stages

601 of succession, have been shown to have high levels of host specificity (Last et al., 1987).

602 Consequently, increased plant richness is likely to be associated with increased fungal

603 diversity (Read, 1994). Compared with the bacterial communities, the fungal communities

604 had low equitability, with a few dominants and many rare species. This was particularly

605 marked on the youngest terrain. Inequitable community structure implies that a handful of

606 species have been successful in dominating resources and excluding their competitors. An

607 increase in equitability with increasing terrain age was consistent with the formation of new

608 fungal niche space as plant succession progressed.

609

610 In contrast to changes in fungal community structure, bacterial structure was invariant across

611 the chronosequence. Bacterial richness, diversity and equitability were more-or-less the

612 same on all three sites. Such invariance implies that plant succession had little impact on

613 bacterial community composition. Of course, it is possible that bacterial biomass varied whilst

614 taxonomic composition remained constant (the same point could also be made for the fungi).

615 Furthermore, PCR techniques do not discriminate between active tissue and inactive

616 spores/senesced tissue. Hence ecological interpretations of the data should be treated with

617 care. Further investigation (e.g. using quantitative PCR) would be required to establish if

618 changes in biomass not paralleled by changes in community composition have occurred on

619 Hekla's lava flows. However, given that microbial biomass is largely determined by the

620 availability of SOM, major changes with time seem unlikely. A number of authors have 
621

622

623

624

625

626

627

628

629

630

631

632

633

634

635

636

637

638

639

640

641

642

643

644

645

646

647

648

649

reported systematic increases in the ratio of fungal:bacterial biomass over time as soils acidify. It is not possible to say whether or not this has occurred with the current dataset but, again, it seems unlikely given the constancy of soil $\mathrm{pH}$ across the sites.

\section{Conclusions}

The results of this study revealed differences in the temporal dynamics of fungal and bacterial communities. Fungal community composition and structure varied during succession: discrete communities formed and these communities became more diverse with increasing terrain age. Changes in community structure occurred without accompanying changes in the soil pH and organic matter content and mirrored changes in vegetation. Our study did not set out to establish a causal link between plant and microbial succession. However, these data strongly suggest a connection that is worthy of further research. It is likely that plant succession led to changes in the type and quality of organic carbon added to soil. Thus, although SOM concentrations did not change overall, the biochemical composition of the organic compounds in the soil may have done. Litter quality (usually measured in terms of C:N ratios) is important to SMCs, as is carbon lability. Indeed, carbon lability, rather than $\mathrm{N}$ content, may be the primary control over decomposition in some settings (Chapin et al., 2002). In this study, increases in the availability and diversity of recalcitrant compounds, e.g. lignin, are probable as shrubby species colonise and spread. An increase in the diversity of these organic substrates could impact on fungal communities. In contrast, bacteria, which can only metabolise more basic products, may not have experienced the same changes in their environment, particularly as $\mathrm{pH}$, which has been demonstrated to structure bacterial communities, did not change. These communities probably became saturated early in the succession and are likely to be more sensitive to changes in soil chemistry than plant community structure per se. This work has relevance for studies of primary succession, which often neglect changes in microbial communities in the soil. It is also relevant for ongoing research into the biogeochemical impact of vegetation change in high-latitude settings. 


\section{Acknowledgements}

653 We thank two anonymous reviewers for their helpful comments. This work was funded by a 654 Small Ecological Project Grant from the British Ecological Society (grant number 2812/3507) 655 and grants from the John Fell Fund, University of Oxford (grant number 091/148) and Trinity 656 College, University of Cambridge. We are grateful for the assistance provided by Steve 657 Boreham (Geography Science Laboratories, University of Cambridge) and James Rolfe 658 (Godwin Laboratory for Palaeoclimate Research, University of Cambridge) in the 659 geochemical analysis of the soil samples and to Gregor Sutherland for field support. 660 


\section{Figure Captions}

662

663

Fig. 1: Location plan. The lava flows are shaded. Contours are at $25 \mathrm{~m}$ intervals.

664

665 Fig. 2: Plant diversity plots (error bars indicate 1 SE).

666

667

Fig. 3: NMDS plot of data from vegetation surveys; sites (transects) are indicated by circles

(black $=1845$ transects, grey $=1389$ transects, white $=1158$ transects), species by crosses .

Key to species: $1=R$. lanuginosum; $2=E$. nigrum; $3=S$. vesuvianum; $4=P$. alpina; $5=S$.

herbacea; 6 = S. lanata; $7=$ C. bigelowii; $8=$ V. uliginosum; $9=$ J. trifidus; $10=$ F. vivipara; $11=$ K. myosuroides; 12 = Umbilicaria sp.; $13=$ Lecidea sp.; $14=$ S. phylicifolia; $15=A$. vinealis; $16=$ G. normanii; $17=$ F. richardsonii; $18=$ T. praecox; $19=$ G. verum; $20=P$. membranacea; $21=$ Peltigera sp.; $22=$ B. vivipara; $23=$ L. multiflora; $24=$ H. splendens; 25

$674=$ D. flexuosa; $26=$ R. geographicum; $27=$ A. uva-ursi; $28=$ C. vulgaris $; 29=$ B. pubescens, $67530=$ Hieracium sp.; $31=$ T. alpinum; $32=$ B. Iunaria; $33=$ P. ciliare .

677 Fig. 4: The relative abundance of putative mycorrhizal fungi on terrain of different ages 678 (expressed as a percentage of the total number of fungal sequences from each lava flow).

679 Terrain age increases from left to right.

680

681 Fig. 5: Microbial diversity statistics. The bars indicate 95\% confidence intervals for samples 682 where random selection (without replacement) was used to standardise sample size. There 683 are no confidence intervals for fungal diversity on the 1158 lava flow, as this sample had the 684 lowest aggregate number of reads(2046). The units on the $y$-axis of $4 a$ ) refer to the number of OTUs clustered by their similarity to each other ( $97 \%$ similarity for the bacteria, $93 \%$

686 similarity for the fungi).

688 Fig. 6: Fungal and bacterial NMDS plots. Sites (transects) are indicated by circles (black = 6891845 transects, grey $=1389$ transects, white $=1158$ transects), OTUs (grouped at 93\% 
690 similarity for fungi and $97 \%$ similarity for bacteria) by crosses. Sites HK-3 and HK-4 are so

691 similar that they overlap. Only the most abundant OTUs (i.e. those accounting for more than $6921 \%$ of the reads in any sample) were used in the analysis.

693 


\section{References}

695

696

697

Abarenkov, K., Nilsson, R.H., Larsson, K.-H., Alexander, I.J., Eberhardt, U., Erland, S., 698 Hoiland, K., Kjoller, R., Larsson, E., Pennanen, T., Sen, R., Taylor, A.F.S., Tedersoo, L., Ursing, B.M., Vralstad, T., Liimatainen, K., Peintner, U., Koljalg, U., 2010a. The UNITE database for molecular identification of fungi - recent updates and future perspectives. New 700 Phytologist 186, 281-285. Abarenkov, K., Tedersoo, L., Nilsson, R.H., Vellak, K., Saar, I., Veldre, V., Parmasto, E., Prous, M., Aan, A., Ots, M., Kurina, O., Ostonen, I., Jogeva, J., Halapuu, S., Poldmaa, K., Toots, M., Truu, J., Larsson, K.-H., Koljalg, U., 2010b. PlutoF-a Web Based Workbench for 704 Ecological and Taxonomic Research, with an Online Implementation for Fungal ITS 705 Sequences. Evolutionary Bioinformatics 6, 189-196. Amend, A.S., Seifert, K.A., Bruns, T.D., 2010. Quantifying microbial communities with 454 pyrosequencing: does read abundance count? Molecular Biology 19, 5555-5565. Arnalds, O., 2004. Volcanic soils of Iceland. Catena 56, 3-20.

Arnalds, O., Gisladdottir, F.O., Orradottir, B., 2012. Determination of aeolian transport rates of volcanic soils in Iceland. Geomorphology 167-168, 4-12.

711 Bardgett, R.D., Bowman, W.D., Kaufmann, R., Schmidt, S.K., 2005. Linking aboveground 712 and belowground communities: a temporal approach. Trends in Ecology and Evolution 20, $713 \quad 634-641$.

714 Bjarnason, Á.H., 1991. Vegetation on lava fields in the Hekla area, Iceland. Acta 715 Phytogeographica Suecica, Uppsala, 111 pp.

716 Blaalid, R., Carlsen, T., Kumar, S., Halvorsen, R., Ugland, K.I., Fontana, G., Kauserud, H., 717 2012. Changes in the root-associated fungal communities along a primary succession 718 gradient analysed by 454 pyrosequencing. Molecular Ecology 21, 1897-1908.

719 Chapin, F.S., Matson, P.A., Mooney, H.A., 2002. Principles of Terrestrial Ecosystem 720 Ecology. Springer-Verlag, New York. 
Chapin, F.S., Walker, L.R., Fastie, C.L., Sharman, L.C., 1994. Mechanisms of primary succession following deglaciation at Glacier Bay, Alaska. Ecological Monographs 64, 149 175

Chen, M., Ma, L.Q., 2001. Comparison of three aqua regia digestion methods for twenty Florida soils. Soil Science Society of America Journal 65, 491-499.

Cutler, N., 2010. Long-term primary succession: a comparison of non-spatial and spatially explicit inferential techniques. Plant Ecology 208, 123-136.

Cutler, N., 2011. Nutrient limitation during long-term ecosystem development inferred from a mat-forming moss. The Bryologist 114, 204-214.

Cutler, N.A., Belyea, L.R., Dugmore, A.J., 2008. The spatiotemporal dynamics of a primary succession. Journal of Ecology 96, 231-246.

DeLuca, T.H., Zackrisson, O., Nilsson, M.-C., Sellstedt, A., 2002. Quantifying nitrogenfixation in feather moss carpets of boreal forests. Nature 419, 917-920.

Edgar, R.C., Haas, B.J., Clemente, J.C., Quince, C., Knight, R., 2011. UCHIME improves sensitivity and speed of chimera detection. Bioinformatics 27, 2194-2200.

Faith, D.P., Minchin, P.R., Belbin, L., 1987. Compositional dissimilarity as a robust measure of ecological distance. Plant Ecology 69, 57-68.

Gardes, M., Bruns, T.D., 1993. ITS primers with enhanced specificity for Basidiomycetes application to the identification of mycorrhizae and rusts. Molecular Ecology 2, 113-118.

Green, J.L., Bohannan, B.J.M., 2006. Spatial scaling of microbial biodiversity. Trends in Ecology and Evolution 21, 501-507.

Greipsson, S., 2012. Catastrophic soil erosion in Iceland: impact of long-term climate change, compounded natural disturbances and human driven land-use changes. Catena 98. Grelet, G.-A., Johnson, D., Paterson, E., Anderson, I.C., Alexander, I.J., 2009. Reciprocal carbon and nitrogen transfer between an ericaceous dwarf shrub and fungi isolated from Piceirhiza bicolorata ectomycorrhizas. New Phytologist 182, 359-366.

Griffiths, R.I., Thomson, B.C., James, P., Bell, T., Bailey, M., Whiteley, A.S., 2011. The bacterial biogeography of British soils. Environmental Microbiology 13, 1642-1654. 
749

750

751

752

753

754

755

756

757

758

759

760

761

762

763

764

765

766

767

768

769

770

771

772

773

774

775

776

777

Heiri, O., Lotter, A.F., Lemcke, G., 2001. Loss on ignition as a method for estimating organic and carbonate content in sediments: reproducibility and comparability of results. Journal of Palaeolimnology 25, 101-110.

Henriksson, E., Henriksson, L.E., Norrman, J.O., Nyman, P.O., 1987. Biological dinitrogen fixation (acetylene reduction) exhibited by blue-green algae (cyanobacteria) in association with mosses gathered on Surtsey, Iceland. Arctic and Alpine Research 19, 432-436.

Hibbett, D.S., Ohman, A., Glotzer, D., Nuhn, M., Kirk, P., Nilsson, R.H., 2011. Progress in molecular and morphological taxon discovery in Fungi and options for formal classification of environmental sequences. Fungal Biology Reviews 25, 38-47.

Jumpponen, A., 2003. Soil fungal community assembly in a primary successional glacier forefront ecosystem as inferred from rDNA sequence analysis. New Phytologist 158, 569578.

Killham, K., 1994. Soil Ecology. Cambridge University Press, Cambridge.

Kirk, J.L., Beaudette, L.A., Hart, M., Moutoglis, P., Klironomos, J.N., Lee, H., Trevors, J.T., 2004. Methods of studying soil microbial diversity. Journal of Microbiological Methods 58, 169-188.

Knelman, J.E., Legg, T.M., O'Neill, S.P., Washenberger, C.L., González, A., Cleveland, C.C., Nemergut, D.R., 2012. Bacterial community structure and function change in association with colonizer plants during early primary succession in a glacier forefield. Soil Biology and Biochemistry 46, 172-180.

Kristinsson, H., 1998. A guide to the flowering plants and ferns of Iceland. Mal og Melling, Reykjavik.

Last, F.T., Dighton, J., Mason, P.A., 1987. Successions of sheathing mycorrhizal fungi. Trends in Ecology and Evolution 2, 157-161.

Lepš, J., Rejmánek, M., 1991. Convergence or divergence: what should we expect from vegetation succession? Oikos 62, 261-264.

Lord, N.S., Kaplan, C.W., Shank, P., Kitts, C.L., Elrod, S.L., 2002. Assessment of fungal diversity using terminal restriction fragment (TRF) pattern analysis: comparison of $18 \mathrm{~S}$ and ITS ribosomal regions. FEMS Microbiology Ecology 42, 327-337. 
778

779

780

781

782

783

784

785

786

787

788

789

790

791

792

793

794

795

796

797

798

799

800

801

802

803

804

805

Matthews, J.A., 1992. The ecology of recently-deglaciated terrain: a geoecological approach to glacier forelands and primary succession. Cambridge University Press, Cambridge. Mitchell, R.J., Campbell, C.D., Chapman, S.J., Cameron, C.M., 2010. The ecological engineering impact of a single tree species on the soil microbial community. Journal of Ecology 98, 50-61.

Muyzer, G., Dewaal, E.C., Uitterlinden, A.G., 1993. Profiling of complex microbial populations by denaturing gradient gel-electrophoresis analysis of polymerase chain reaction-amplified genes coding for $16 \mathrm{~S}$ ribosomal RNA. Applied and Environmental Microbiology 59, 695-700. Nemergut, D.R., Anderson, S.P., Cleveland, C.C., Martin, A.P., Miller, A.E., Seimon, A., Schmidt, S.K., 2007. Microbial community succession in an unvegetated, recently deglaciated soil. Microbial Ecology 53, 110-122.

Nilsson, R.H., Veldre, V., Hartmann, M., Unterseher, M., Amend, A., Bergsten, J., Kristiansson, E., Ryberg, M., Jumpponen, A., Abarenkov, K., 2010. An open source software package for automated extraction of ITS1 and ITS2 from fungal ITS sequences for use in high-throughput community assays and molecular ecology. Fungal Ecology 3, 284-287. Ohtonen, R., Fritze, H., Pennanen, T., Jumpponen, A., Trappe, J., 1999. Ecosystem properties and microbial community changes in primary succession on a glacier forefront. Oecologia 119, 239-246.

Oksanen, J., Blanchet, F.G., Kindt, R., Legendre, P., O'Hara, R.G., Simpson, G.L., Solymos, P., Stevens, M.H.H., Wagner, H., 2010. vegan: Community Ecology Package, 1.17-0 ed.

Osono, T., Trofymow, J.A., 2012. Microfungal diversity associated with Kindbergia oregana in successional forests in British Columbia. Ecological Research 27, 35-41.

Quast, C., Pruesse, E., Yilmaz, P., Gerken, J., Schweer, T., Yarza, P., Peplies, J., Gloeckner, F.O., 2013. The SILVA ribosomal RNA gene database project: improved data processing and web-based tools. Nucleic Acids Research 41, D590-D596.

Quince, C., Lanzen, A., Curtis, T.P., Davenport, R.J., Hall, N., Head, I.M., Read, L.F., Sloan, W.T., 2009. Accurate determination of microbial diversity from 454 pyrosequencing data. Nature Methods 6, 639-U627. 
Quince, C., Lanzen, A., Davenport, R.J., Turnbaugh, P.J., 2011. Removing noise from

807

808

809

810

811

812

813

814

815

816

817

818

819

820

821

822

823

824

825

826

827

828

829

830

831

832

833

834

pyrosequenced amplicons, BMC Bioinformatics.

Read, D.J., 1994. Plant-microbe mutualisms and community structure, In: Schulze, E.D., Mooney, H.A. (Eds.), Biodiversity and Ecosystem Function. Springer-Verlag, New York, pp. 181-209.

Rinaldi, A.C., Comandini, O., Kuyper, T.W., 2008. Ectomycorrhizal fungal diversity: separating the wheat from the chaff. Fungal Diversity 33, 1-45.

Rogers, S.O., Bendich, A.J., 1988. Extraction of DNA from plant tissues, In: Gelvin, S.V., Shilperoort, R.A., Verma, D.P.S. (Eds.), Plant Molecular Biology Manual. Kluwer Academic, Dordrecht, pp. 1-10.

Schaaf, W., Bens, O., Fischer, A., Gerke, H.H., Gerwin, W., Grünewald, U., Holländer, H.M., Kögel-Knabner, I., Mutz, M., Schloter, M., Schulin, R., Veste, M., Winter, S., Hüttl, R.F., 2011. Patterns and processes of initial terrestrial-ecosystem development. Journal of Plant Nutrition and Soil Science 174, 229-239.

Schloss, P.D., Gevers, D., Westcott, S.L., 2011. Reducing the Effects of PCR Amplification and Sequencing Artifacts on 16S rRNA-Based Studies. PLoS ONE 6.

Schloss, P.D., Westcott, S.L., Ryabin, T., Hall, J.R., Hartmann, M., Hollister, E.B.,

Lesniewski, R.A., Oakley, B.B., Parks, D.H., Robinson, C.J., Sahl, J.W., Stres, B., Thallinger, G.G., Van Horn, D.J., Weber, C.F., 2009. Introducing mothur: Open-Source, PlatformIndependent, Community-Supported Software for Describing and Comparing Microbial Communities. Applied and Environmental Microbiology 75, 7537-7541.

Schütte, U.M.E., Abdo, Z., Bent, S.J., Williams, C.J., Schneider, G.M., Solheim, B., Forney, L.J., 2009. Bacterial succession in a glacier foreland of the High Arctic. The ISME Journal 3, 1258-1268.

Sigler, W.V., Crivii, S., Zeyer, J., 2002. Bacterial succession in glacial forefield soils characterized by community structure, activity and opportunistic growth dynamics. Microbial Ecology 44, 306-316.

Sørensen, T.A., 1948. Method of establishing groups of equal amplitude in plant sociology based on similarity of species content, and its application to analyses of the vegetation on 
Danish commons. Biologiske Skrifter, det Kongelige Danske Videnskabernes Selskab 5, 1-

836

837

838

839

840

841

842

843

844

845

846

847

848

849

850

851

852

853

854

855

856

857

858

859

860

861

862

863

34.

Stevens, P.R., Walker, T.W., 1970. The chronosequence concept and soil formation.

Quarterly Review of Biology 45, 333-350.

Tscherko, D., Rustmeier, J., Richter, A., Wanek, W., Kandeler, E., 2003. Functional diversity of the soil microflora in primary succession across two glacier forelands in the Central Alps.

European Journal of Soil Science 54, 685-696.

Uroz, S., Oger, P., Morin, E., Frey-Klett, P., 2012. Distinct ectomycorrhizospheres share similar bacterial communities as revealed by pyrosequencing-based analysis of 16S rRNA genes. Applied and Environmental Microbiology 78, 3020-3024.

van der Heijden, M.G.A., Bardgett, R.D., van Straalen, N.M., 2008. The unseen majority: soil microbes as drivers of plant diversity and productivity in terrestrial ecosystems. Ecology

Letters 11, 296-310.

Vitousek, P.M., 1994. Potential nitrogen fixation during primary succession in Hawaii Volcanoes National Park. Biotropica 26, 234-240.

Walker, L.R., del Moral, R., 2003. Primary Succession and Ecosystem Rehabilitation.

Cambridge Univ Press, Cambridge.

Walker, L.R., Wardle, D.A., Bardgett, R.D., Clarkson, B.D., 2010. The use of chronosequences in studies of ecological succession and soil development. Journal of Ecology 98, 725-736.

Wang, Q., Garrity, G.M., Tiedje, J.M., Cole, J.R., 2007. Naive Bayesian classifier for rapid assignment of rRNA sequences into the new bacterial taxonomy. Applied and Environmental Microbiology 73, 5261-5267.

Wang, Y., Qian, P.-Y., 2009. Conservative Fragments in Bacterial 16S rRNA Genes and Primer Design for 16S Ribosomal DNA Amplicons in Metagenomic Studies. PLoS ONE 4.

Wardle, D.A., Walker, L.R., Bardgett, R.D., 2004. Ecosystem properties and forest decline in contrasting long-term chronosequences. Science 305, 509-513.

White, T.J., Bruns, T., Lee, S., Taylor, J., 1990. Amplification and direct sequencing of fungal ribosomal RNA genes for phylogenetics, In: Innis, M.A., Gelfand, D.H., Sninsky, J.J., White, 
864 T.J. (Eds.), PCR Protocols: A Guide to Methods and Applications. Academic Press, San

865 Diego, pp. 315-322.

866 Woods, K.D., 2007. Predictability, contingency, and convergence in late succession: slow

867 systems and complex data-sets. Journal of Vegetation Science 18, 543-554.

868 Zak, D.R., Holmes, W.E., White, D.C., Peacock, A.D., Tilman, D., 2003. Plant diversity, soil

869 microbial communities, and ecosystem function: are there any links? Ecology 84, 2042-2050.

870

871

872

873

874

875

876

877

878

879

880

881

882

883

884

885

886

887

888

889

890

891

892 
Figure 1

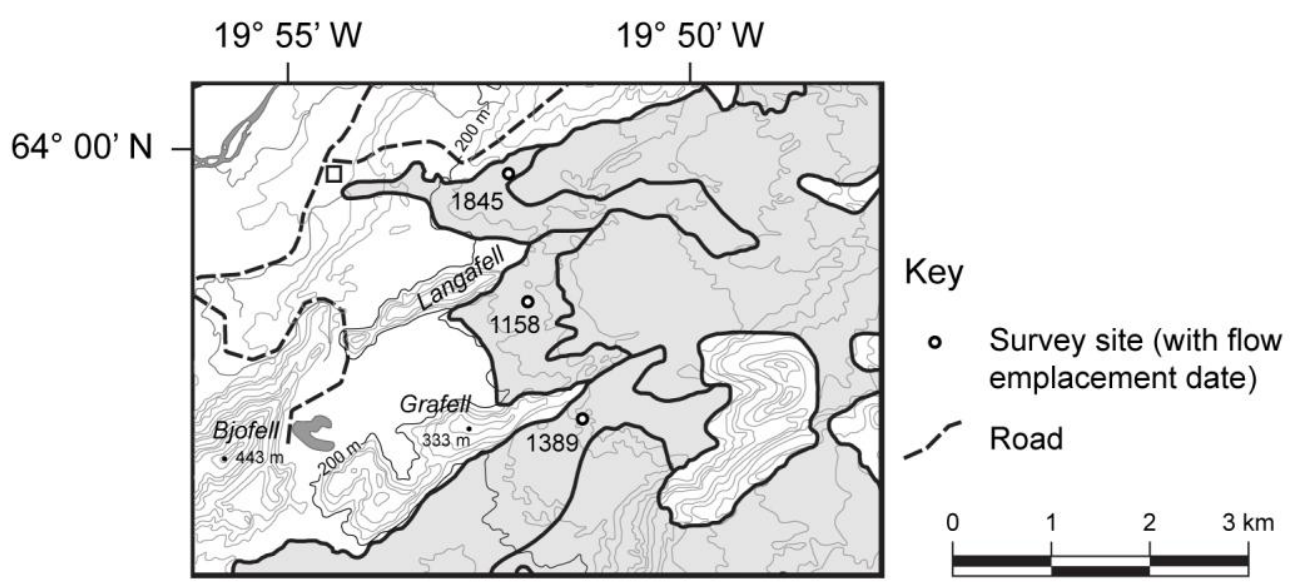

894

895 Figure 2
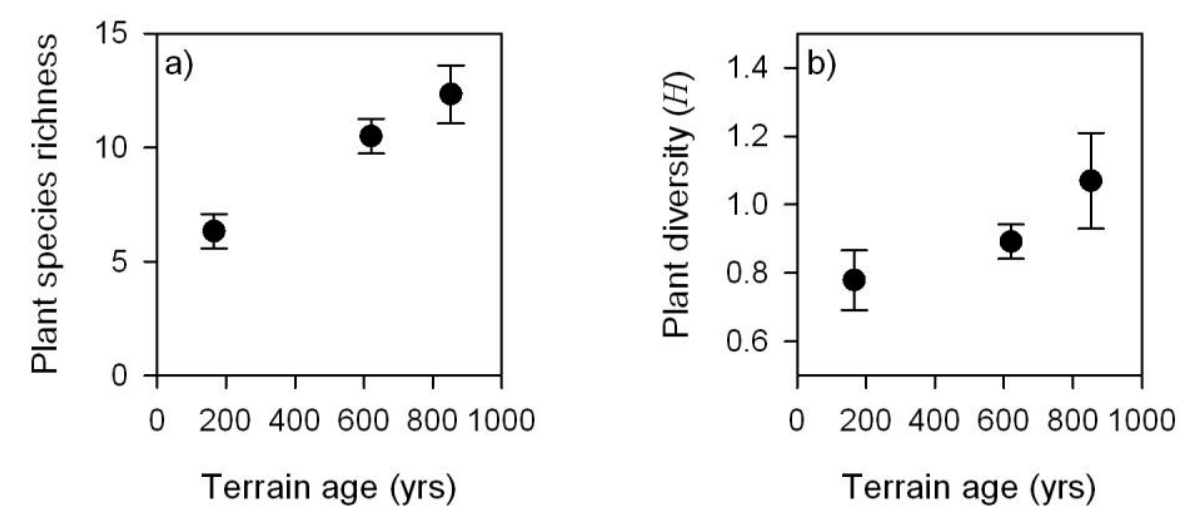

896

Figure 3

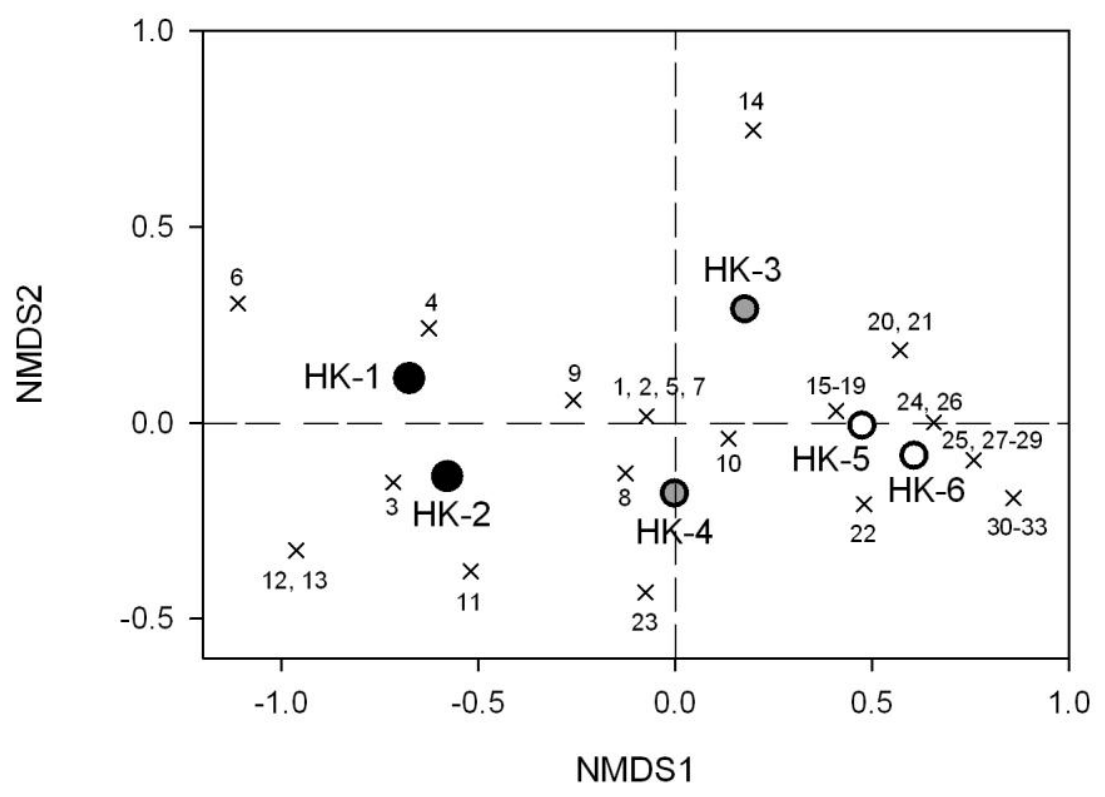




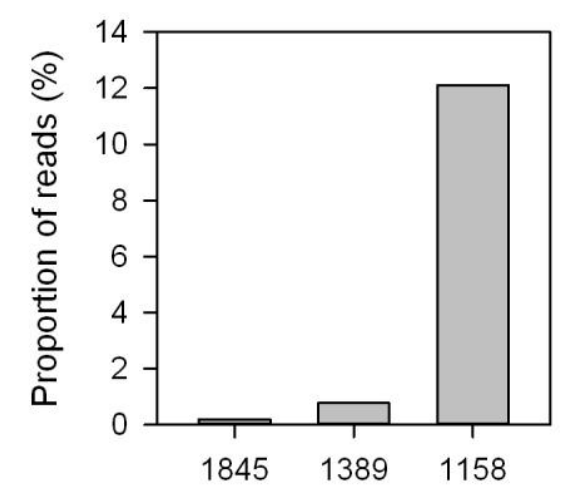

$901 \quad$ Figure 5

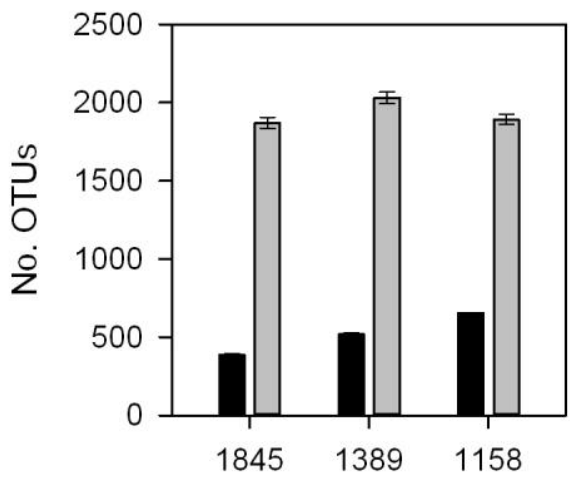

Flow emplacement date

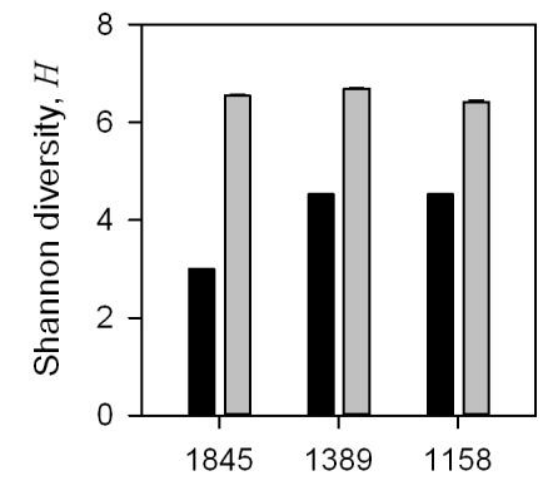

Flow emplacement date

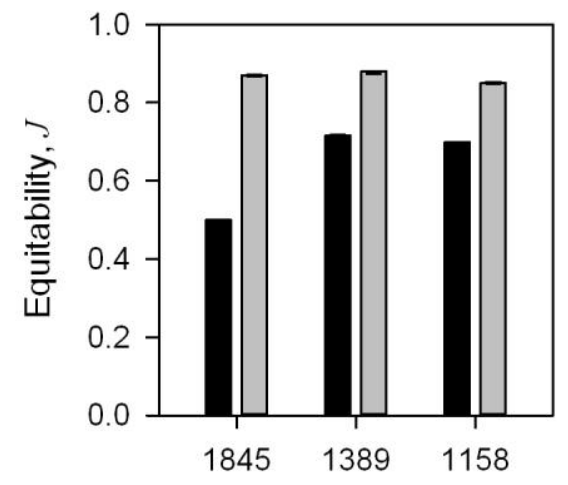

Flow emplacement date

\section{Fungi}

Bacteria

902

903

904

905

906

907

908

909

910

911 
Figure 6
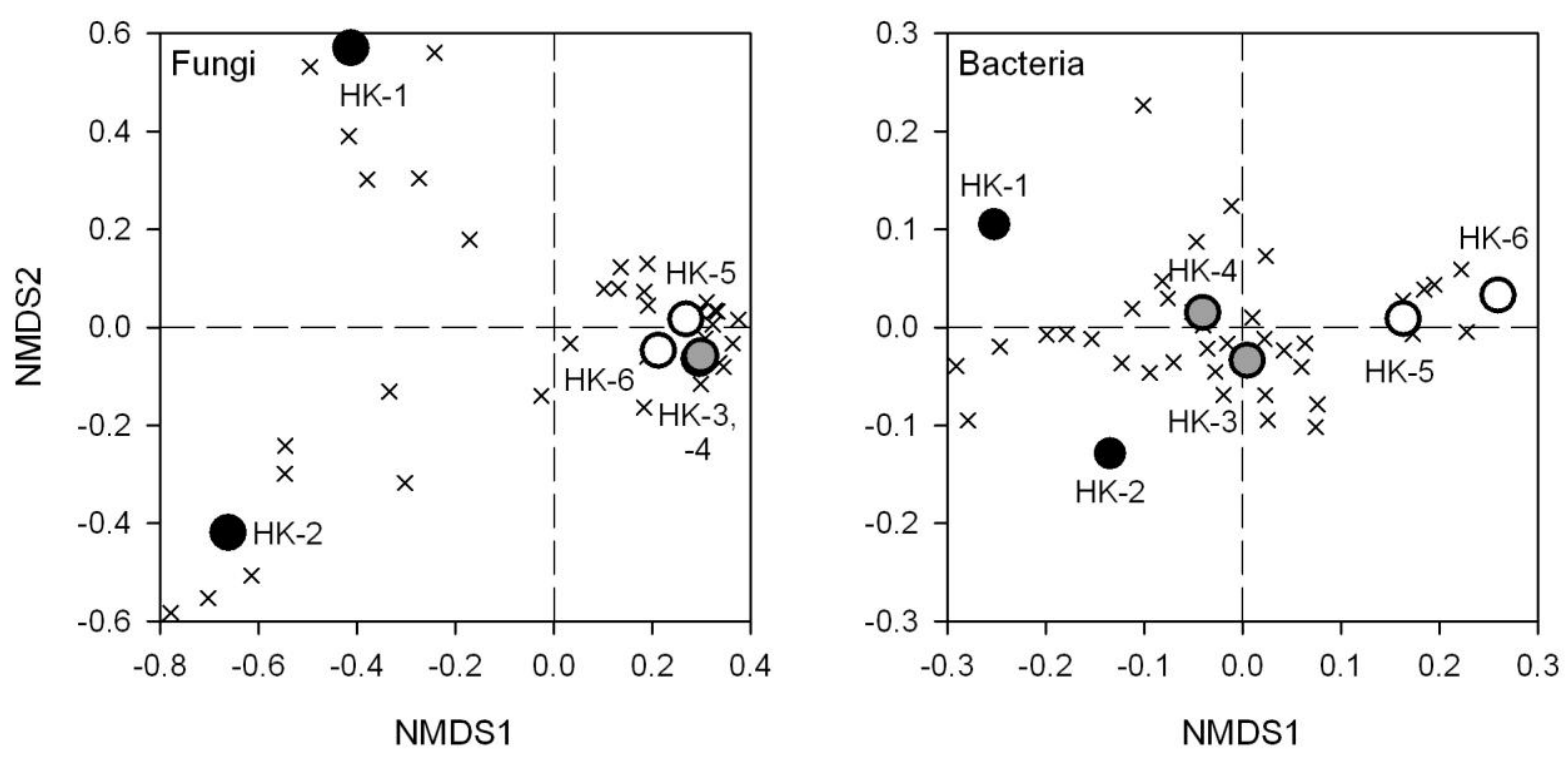

913

914

915

916

917

918

919

920

921

922

923

924

925

926

927

928

929

930

931 


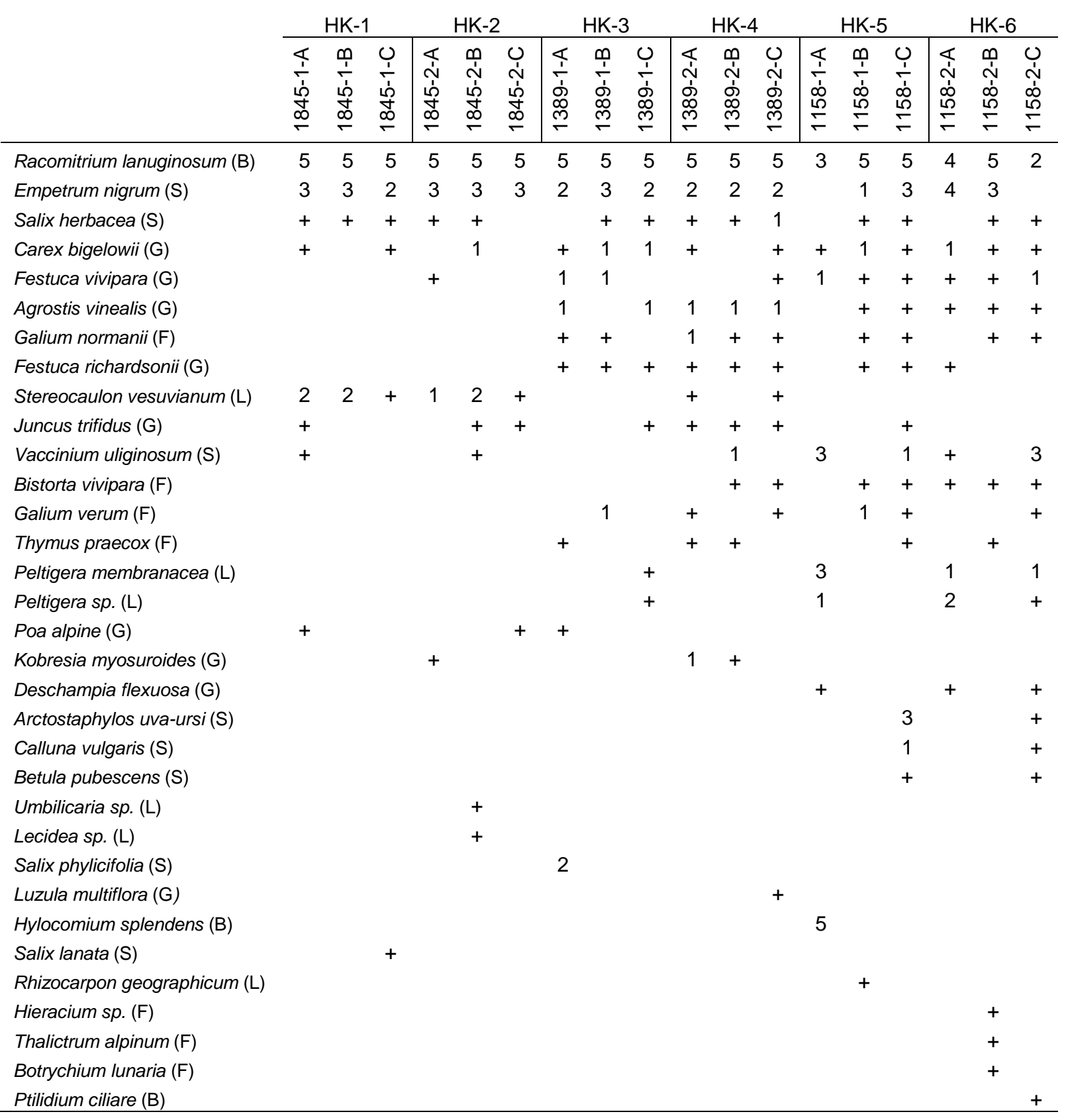

934 Table 1: Vegetation survey results based on the Braun Blanquet abundance scale $(+=$

935 present, but with $<1 \%$ cover; $1=1-5 \%$ cover; $2=6-25 \%$ cover $; 3=26-50 \%$ cover $; 4=51$ -

$93675 \%$ cover; $5=76-100 \%$ cover). Pooled pyrosequencing samples are indicated on the top

937 line of the table; quadrat identifiers, formatted as flow emplacement date - transect number -

938 quadrat letter are in the row below (each pyrosequencing sample comprises material from

939 three quadrats). Vegetation type is indicated by the letters S (shrub), G (graminoid), F (forb),

940 B (bryophyte) and L (lichen) after the species name. 


\begin{tabular}{lccc} 
& \multicolumn{3}{c}{ Terrain age (years) } \\
Soil property & 165 & 621 & 852 \\
\hline Soil pH range; mean & $5.6-6.5 ; 6.0$ & $6.0-6.9 ; 6.3$ & $5.3-6.6 ; 6.0$ \\
SOM content (\%) & $11.4 \pm 1.0$ & $10.3 \pm 0.9$ & $10.8 \pm 0.9$ \\
Mean grain size (\% by vol.) & & & \\
$\quad$ Coarse sand & $16.5 \pm 1.6$ & $22.7 \pm 1.2$ & $24.7 \pm 1.2$ \\
$\quad$ Fine sand & $76.9 \pm 1.5$ & $72 \pm 1.1$ & $70.8 \pm 1.2$ \\
$\quad$ Silt & $6.3 \pm 0.2$ & $5.3 \pm 0.3$ & $4.5 \pm 0.2$ \\
$\quad$ Clay & $0.3 \pm 0.1$ & $0.1 \pm 0.1$ & 0.0 \\
Total $\mathrm{N}(\%)$ & $0.09 \pm 0.01$ & $0.11 \pm 0.01$ & $0.10 \pm 0.01$ \\
Total $\mathrm{P}_{\mathrm{M}}\left(\mathrm{mg} \mathrm{l}^{-1}\right)$ & $9.7 \pm 0.5$ & $12.1 \pm 0.5$ & $13.4 \pm 0.3$ \\
Total $\mathrm{P}_{\mathrm{O}}\left(\mathrm{mg} \mathrm{l}^{-1}\right)$ & $\mathrm{NA}$ & $8.7 \pm 1.4$ & $7.6 \pm 1.5$ \\
Total $\mathrm{K}_{\mathrm{M}}\left(\mathrm{mg} \mathrm{l}^{-1}\right)$ & $0.8 \pm 0.1$ & $0.9 \pm 0.1$ & $1.1 \pm 0.1$ \\
Total $\mathrm{K}_{\mathrm{O}}\left(\mathrm{mg} \mathrm{l}^{-1}\right)$ & $\mathrm{NA}$ & $0.4 \pm 0.1$ & $0.4 \pm 0.1$ \\
\hline
\end{tabular}

943 Table 2: Summary of soil data for the three different terrain ages. The subscript 'M' refers to

944 the mineral soil, the subscript ' $O$ ' to the overlying organic layer identified on the 1389 and 9451158 sites only.

946

947

948

949

950

951

952

953

954

955

956

957

958 
Abundance $(\mathrm{N}=$ no. reads, $\%=$ percent of reads)

\begin{tabular}{|c|c|c|c|c|c|c|c|c|c|c|c|c|c|}
\hline \multirow[b]{2}{*}{ Fungal hits } & \multirow[b]{2}{*}{ Phylum } & & \multicolumn{2}{|c|}{ HK-2 } & \multicolumn{2}{|c|}{ HK-3 } & \multicolumn{2}{|c|}{ HK-4 } & \multicolumn{2}{|c|}{$\begin{array}{l}\text { HK-5 } \\
(852)\end{array}$} & \multicolumn{2}{|c|}{ HK-6 } \\
\hline & & $\mathrm{N}$ & $\%$ & $\mathrm{~N}$ & $\%$ & $\mathrm{~N}$ & $\%$ & $\mathrm{~N}$ & $\%$ & $\mathrm{~N}$ & $\%$ & $\mathrm{~N}$ & $\%$ \\
\hline Batcheloromyces sp. & Ascomycota & 14 & 0.7 & 4 & 0.2 & 378 & 18.5 & 644 & 31.5 & 293 & 14.3 & 552 & 27.0 \\
\hline Hygrocybe spp. & Basidiomycota & 874 & 42.7 & 0 & 0.0 & 169 & 8.3 & 42 & 2.1 & 24 & 1.2 & 0 & 0.0 \\
\hline Epicoccum sp. & Ascomycota & 0 & 0.0 & 0 & 0.0 & 53 & 2.6 & 110 & 5.4 & 187 & 9.1 & 14 & 0.7 \\
\hline Mortierella sp. & Zygomycota & 7 & 0.3 & 60 & 2.9 & 57 & 2.8 & 18 & 0.9 & 81 & 4.0 & 86 & 4.2 \\
\hline Cryptococcus sp. & Basidiomycota & 0 & 0.0 & 0 & 0.0 & 0 & 0.0 & 1 & 0.0 & 185 & 9.0 & 44 & 2.2 \\
\hline Clavaria argillacea & Basidiomycota & 156 & 7.6 & 30 & 1.5 & 11 & 0.5 & 7 & 0.3 & 4 & 0.2 & 19 & 0.9 \\
\hline Russula spp. & Ascomycota & 3 & 0.1 & 0 & 0.0 & 0 & 0.0 & 0 & 0.0 & 79 & 3.9 & 118 & 5.8 \\
\hline Meliniomyces bicolor & Basidiomycota & 2 & 0.1 & 3 & 0.1 & 0 & 0.0 & 0 & 0.0 & 107 & 5.2 & 4 & 0.2 \\
\hline
\end{tabular}

\begin{tabular}{|c|c|c|c|c|c|c|c|c|c|c|c|c|}
\hline \multirow[b]{2}{*}{ Bacterial hits } & \multicolumn{2}{|c|}{ HK-1 } & \multicolumn{2}{|c|}{ HK-2 } & \multicolumn{2}{|c|}{ HK-3 } & \multicolumn{2}{|c|}{ HK-4 } & \multicolumn{2}{|c|}{ HK-5 } & \multicolumn{2}{|c|}{ HK-6 } \\
\hline & $\mathrm{N}$ & $\%$ & $\mathrm{~N}$ & $\%$ & $\mathrm{~N}$ & $\%$ & $\mathrm{~N}$ & $\%$ & $\mathrm{~N}$ & $\%$ & $\mathrm{~N}$ & $\%$ \\
\hline Acidobacteria & 1235 & 30.4 & 937 & 23.0 & 972 & 23.9 & 1113 & 27.4 & 737 & 18.1 & 694 & 17.1 \\
\hline Proteobacteria (Alpha) & 830 & 20.4 & 1088 & 26.7 & 866 & 21.3 & 672 & 16.5 & 858 & 21.1 & 777 & 19.1 \\
\hline Proteobacteria (Beta) & 752 & 18.5 & 1118 & 27.5 & 935 & 23.0 & 877 & 21.6 & 1142 & 28.1 & 1101 & 27.1 \\
\hline Proteobacteria (Delta) & 141 & 3.5 & 76 & 1.9 & 134 & 3.3 & 150 & 3.7 & 132 & 3.2 & 105 & 2.6 \\
\hline Proteobacteria (Gamma) & 173 & 4.3 & 172 & 4.2 & 184 & 4.5 & 142 & 3.5 & 265 & 6.5 & 215 & 5.3 \\
\hline Actinobacteria & 278 & 6.8 & 195 & 4.8 & 303 & 7.4 & 275 & 6.8 & 342 & 8.4 & 454 & 11.2 \\
\hline Verrucomicrobia & 74 & 1.8 & 43 & 1.1 & 102 & 2.5 & 116 & 2.9 & 33 & 0.8 & 82 & 2.0 \\
\hline
\end{tabular}

Table 3: Selected fungal and bacterial taxa at a genus and phylum level, respectively. The fungal taxa shown are varieties that account for $>1 \%$ of the total number of reads (aggregated across all sites) and were resolvable to at least genus level. The relative abundance of each taxonomic group is expressed as a percentage of the total number of sequence reads from each transect. The number of reads from each transect was standardised to match the smallest sample by random sub-sampling (2046 reads for fungi and 4069 for the bacteria). The most abundant fungal groups from HK-2 were only resolved to a sub-phylum level and are not shown, hence the lack of obvious dominants. 
Plants

\begin{tabular}{lccccc} 
& HK-1 & HK-2 & HK-3 & HK-4 & HK-5 \\
\hline HK-2 & 76 & & & & \\
HK-3 & 50 & 52 & & & \\
HK-4 & 56 & 64 & 71 & & \\
HK-5 & 40 & 42 & 72 & 70 & \\
HK-6 & 32 & 35 & 65 & 63 & $\mathbf{8 4}$ \\
\hline
\end{tabular}

\section{Fungi}

\begin{tabular}{lccccc} 
& HK-1 & HK-2 & HK-3 & HK-4 & HK-5 \\
\hline HK-2 & 63 & & & & \\
HK-3 & 71 & 66 & & & \\
HK-4 & 67 & 67 & 81 & & \\
HK-5 & 70 & 62 & 86 & 83 & \\
HK-6 & 87 & 69 & 86 & 76 & 79 \\
\hline
\end{tabular}

Bacteria

\begin{tabular}{lccccc} 
& HK-1 & HK-2 & HK-3 & HK-4 & HK-5 \\
\hline HK-2 & 96 & & & & \\
HK-3 & 96 & 95 & & & \\
HK-4 & 97 & 96 & 99 & & \\
HK-5 & 95 & 93 & 99 & 94 & \\
HK-6 & 91 & 89 & 95 & 93 & 96 \\
\hline
\end{tabular}

966

967 Table 4: Percent similarity data $(100 \%=$ identical community structure $)$ calculated from OTU

968 presence-absence data. Values comparing adjacent transects on terrain of the same age are 969 indicated in bold. 